\title{
Early changes in apoptosis and proliferation following primary chemotherapy for breast cancer
}

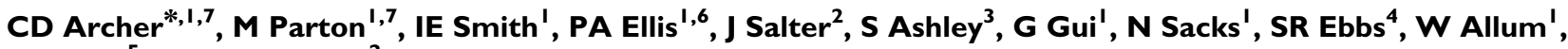 \\ N Nasiri ${ }^{5}$ and $M$ Dowsett $^{2}$
}

'Breast Unit, Royal Marsden NHS Trust, Fulham Road, London SW3 6Jl, UK; ${ }^{2}$ Academic Department of Biochemistry, Royal Marsden NHS Trust, Fulham Road, London SW3 6J, UK; ${ }^{3}$ Academic Department of Computing, Royal Marsden NHS Trust, Fulham Road, London SW3 6J, UK; ${ }^{4}$ Mayday University Hospital, London Road, Croydon, Surrey CR7 7YE, UK; ${ }^{5}$ Academic Department of Pathology, Royal Marsden NHS Trust, Fulham Road, London SW3 6JJ, UK

Patients undergoing primary chemotherapy for invasive breast cancer consented to a core biopsy of the invasive breast primary preand $24 \mathrm{~h}$ postchemotherapy. The resulting tissue was analysed for apoptosis, Ki67, ER and HER-2 using immunohistochemical techniques. These data were then used to evaluate the relationship between these biological markers and response to chemotherapy and overall survival. Response rate to chemotherapy in this group was $86 \%, 16$ patients $(25 \%)$ achieved a clinical complete response and $4 \mathrm{I}$ (63\%) a partial response. Prechemotherapy there was a significant correlation between Ki67 and apoptotic index (Al), $r=0.6$, $(P<0.00 \mathrm{I})$. A significant rise in $\mathrm{Al}(\mathrm{P}<0.00 \mathrm{I})$, and fall in Ki67 $(P=0.002)$ was seen $24 \mathrm{~h}$ following chemotherapy. No relationship was seen between pretreatment $\mathrm{Al}$ and clinical response, but higher Ki67 and growth index (Ki67/Al ratio, Gl) did correlate with clinical response (both $r=0.31, P<0.025$ ). No correlation was seen between the change in $\mathrm{Al}$ or Ki67 at $24 \mathrm{~h}$ and clinical response or survival. Significant changes in apoptosis and proliferation can be demonstrated $24 \mathrm{~h}$ following chemotherapy, but these changes do not relate to clinical response or outcome in this study. Pretreatment proliferation and $\mathrm{Gl}$ are however predictive of response to chemotherapy in breast cancer.

British Journal of Cancer (2003) 89, I035-104I. doi:I0.1038/sj.bjc.660II73 www.bjcancer.com

(c) 2003 Cancer Research UK

Keywords: breast cancer; apoptosis; proliferation; chemotherapy

The use of primary or preoperative chemotherapy emerged as a result of the good response rates seen with the treatment of locally advanced breast cancers with chemotherapy (Swain et al, 1987; Hortobagyi et al, 1988). In large but operable tumours, primary chemotherapy has also shown high response rates, allowing more conservative surgery. This reduces the need for mastectomy, without affecting the local recurrence rate (Powles et al, 1995; Smith et al, 1995; Fisher et al, 1997), and without compromising survival (Fisher et al, 1998).

Another advantage of primary chemotherapy is that it provides an in vivo model by which to study the effects of chemotherapy on the primary tumour (Forrest et al, 1986). Adjuvant chemotherapy has improved the outcome for women with breast cancer, through large clinical trials (EBCTCG, 1998a). These trials, however, require many years of follow-up and very large numbers of patients. New approaches are needed to allow more rapid assessment of the large number of new agents presently under development. Clinical

\footnotetext{
* Correspondence: Dr CD Archer, Portsmouth Oncology Centre, St Marys Hospital, Milton Road, Portsmouth, Hampshire PO3 6AD, UK; E-mail: Caroline.Archer@porthosp.nhs.uk

${ }^{7}$ Contributed equally

${ }^{6}$ PA Ellis's current address: Guy's, King's and St Thomas' NHS Trust, UK Received 18 November 2002; revised 12 May 2003; accepted 5 June 2003
}

response to primary chemotherapy is associated with improved survival, (Cameron et al, 1997; Bonadonna et al, 1998; Fisher et al, 1998), but this is an insensitive surrogate since the majority of patients achieve a response. Biological markers, which are predictive of response, might prove to be more sensitive shortterm surrogates of long-term outcome. If this were the case, the use of these markers would substantially increase the speed of drug development, and also tailor chemotherapy more effectively for the individual patient.

Studies in primary chemoendocrine and endocrine therapy have shown that early changes in proliferation, 14-21 days after starting therapy, are significantly associated with clinical response. (Dowsett et al, 1999). An increase in apoptosis following cytotoxic chemotherapy occurs much earlier. In murine mammary tumours, apoptosis has been demonstrated within $24-36 \mathrm{~h}$ of cytotoxic drug administration (Meyn et al, 1994, 1995), and in our earlier preliminary clinical studies significantly increased apoptosis was seen $24 \mathrm{~h}$ after starting chemotherapy (Ellis et al, 1997). A small study has indicated that an early increase in apoptosis as measured in fine-needle aspirates (FNA) by flow cytometry was significantly associated with clinical response in breast cancer, but this methodology was noted to be complicated by problems of precision (Chang et al, 1999). This study used core biopsy material to evaluate the changes in apoptosis and proliferation $24 \mathrm{~h}$ after chemotherapy, and assessed the relationship of those changes with clinical response and survival. 


\section{MATERIALS AND METHODS}

\section{Patient population}

The study period was between February 1995 and March 2001. Patients presenting to the Royal Marsden Hospital with nonmetastatic primary breast cancer of $3 \mathrm{~cm}$ or greater and to be treated with primary chemotherapy were eligible for entry into this study. The diagnosis of invasive breast cancer was made on 14-gauge core biopsy in all patients prior to primary chemotherapy. Following informed consent, patients entering the study had a further core biopsy $24 \mathrm{~h}$ after the start of the first course of chemotherapy, and the material in both biopsies was analysed.

\section{Treatment}

Chemotherapy was anthracycline-based, except two patients who received mitoxantrone. In all, 34 patients received doxorubicinbased, and 30 patients epirubicin-based combination chemotherapy. A total of 38 patients were entered into trials of primary chemotherapy during the study period (Smith et al, 1995, 2000; Eisen et al, 1998), others were treated with standard combination chemotherapy. Tamoxifen was also prescribed to $49(74 \%)$ patients, 27 of whom started tamoxifen during the chemotherapy (although after the $24 \mathrm{~h}$ biopsy), and the remainder following completion of chemotherapy. Chemotherapy was continued for six cycles or until progression, when patients were considered for surgery, which was usually lumpectomy or mastectomy with axillary clearance.

\section{Evaluation of tumour response}

Response was assessed by bidimensional tumour measurements before each cycle of chemotherapy. Response was defined as per WHO criteria (Miller et al, 1981). Pathological evaluation of the tumour postsurgery identified those who had no residual invasive or in situ disease pathological complete response (pCR).

\section{Laboratory methods}

Core biopsies were taken after local anaesthetic infiltration of the skin using a 14-gauge needle on a spring-loaded device. The material obtained was formalin-fixed and paraffin-embedded. Sections $(3 \mu \mathrm{m})$ were cut onto charged slides and left at $37^{\circ} \mathrm{C}$ overnight. These were examined by a Consultant histopathologist $(\mathrm{NN})$, for histological classification (NCGFBS, 1995) and grading where possible (Bloom and Richardson, 1957). Immunohistochemistry for Ki67, ER and HER-2 was performed using a standard avidin-biotin complex technique according to the following methodology, and apoptotic index (AI) assessed using Terminal deoxynucleotidyltransferase-mediated d-UTP nick end labelling (TUNEL) and in situ end-labelling (ISEL) techniques.

Ki67 Sections were dewaxed, hydrated and taken to water and treated with hydrogen peroxidase to neutralise endogenous peroxidases. After antigen retrieval by microwaving in citrate buffer for $5 \mathrm{~min}$ at full power ( $750 \mathrm{~W}$ microwave), normal rabbit serum at a dilution of 1:5 was applied. MIB1 primary antibody (The Binding Site Ltd, UK) was used at a dilution of 1:50, and incubated for an hour at room temperature. All dilutions and washes were with phosphate-buffered saline (PBS). Rabbit anti-mouse serum was applied followed by avidin-biotin complex (ABC) (Dako, Denmark), which was developed by diaminobenzene (DAB) (Sigma, USA), and counterstained with haematoxylin.

HER-2 The sections were treated in a similar fashion as with the MIB1 antibody, except that antigen retrieval was not required. The primary antibody, ICR 12 (Gusterson et al, 1992) was used at a dilution of 1:800, incubated for an hour at room temperature.

Oestrogen receptor (ER) The same staining procedure as for MIB1, with microwave antigen retrieval. The primary antibody used was ID5 (Dako) incubated at a dilution of $1: 100$ for $2 \mathrm{~h}$ at room temperature, according to previously validated conditions (Saccani Jotti et al, 1994).

Apoptotic index In situ end labelling (ISEL) uses biotin-16-dUTP (Boehringer Mannheim) plus the Klenow fragment of Escherichia coli DNA polymerase 1 (Pharmacia) (Wijsman et al, 1993). Terminal deoxynucleotidyltransferase-mediated d-UTP nick end labelling (TUNEL) technique is modified from Gavrieli et al (1992). Both these techniques have been used by our laboratory and have shown equivalent results in breast cancer sections (Mainwaring et al, 1998).

\section{Scoring}

All sections were coded and scored blind to time of biopsy, treatment and clinical outcome by PAE, CDA and MP. Sections were examined under a standard light microscope using a $\times 40$ objective and a $10 \times 10$ eye piece incorporating a graticule. Invasive breast cancer cells only were counted. Ki67 score was defined as a percentage of total number of tumour cells with nuclear staining to the MIB1 antibody over 10 high power fields $(\times 40)$. A tumour was defined as HER-2 positive by the presence of the characteristic membrane staining in over $10 \%$ of the tumour cells. The AI was a percentage score of apoptotic cells from a total of 3000 malignant cells. Unstained apoptotic cells were included if they showed classical morphological features of apoptosis, cytoplasmic condensation and chromatin clumping (Wyllie et al, 1980). Apoptotic bodies not obviously associated with an apoptotic cell were included in the count only when present as clumps. Oestrogen receptor was assessed either with a Histo-score $(\mathrm{H}-$ score) or using a Quickscore that has been previously validated against $H$-score in breast cancer sections. Oestrogen receptor positive was defined as an $H$-score of $>20$ (Detre et al, 1995).

\section{Statistical analysis}

Nonparametric statistics were used. The changes in AI and proliferation during the first $24 \mathrm{~h}$ of chemotherapy were analysed using the Wilcoxon signed-rank test. The relationship at baseline between AI and MIB1 scores was assessed using the Spearman rank correlation, as was the association between biological markers and response. Kaplan-Meier curves were used for survival analysis. No formal powering of the study was conducted, but with 66 patients it would be possible to detect a correlation of 0.40 or greater with $90 \%$ power.

\section{Ethical}

This study was approved by the Research and Ethics Committee of the Royal Marsden NHS Trust. All patients gave written informed consent.

\section{RESULTS}

\section{Clinical results}

A total of 108 patients consented to study entry and had a repeat core biopsy $24 \mathrm{~h}$ after starting chemotherapy. In all, 66 patients had sufficient invasive tissue in both biopsies to be used for analysis of the biological markers, although seven of these did not have enough material to be tested for all parameters. The characteristics of the study population are given in Table 1. 
Table I Demographics and patient characteristics

\begin{tabular}{lc}
\hline Characteristic & No. of patients $(\boldsymbol{n}=\mathbf{6 6})$ \\
\hline Age (years) & \\
Median & $48(32-63)$ \\
Menopausal status & \\
Premenopausal & $39(59 \%)$ \\
Perimenopausal & $3(5 \%)$ \\
Postmenopausal & $24(36 \%)$ \\
Tumour stage & \\
T-2 & $29(44 \%)$ \\
T-3 & $26(39 \%)$ \\
T-4 operable & $1(2 \%)$ \\
T-4 inoperable & $10(15 \%)$ \\
Tumour size (cm) & \\
Median & $5.7(3-20)$ \\
Histology & \\
Ductal & $56(84 \%)$ \\
Lobular & $8(12 \%)$ \\
Ductal+lobular & $1(2 \%)$ \\
Mucinous & $1(2 \%)$ \\
Grade & \\
Gradel & $0(0 \%)$ \\
Grade 2 & $29(44 \%)$ \\
Grade 3 & $34(51.5 \%)$ \\
Unknown & $3(4.5 \%)$ \\
ER status & $43(65 \%)$ \\
Positive & $23(35 \%)$ \\
Negative & $18(27 \%)$ \\
HER-2 status & $48(73 \%)$ \\
Positive & \\
Negative & \\
\hline & \\
\hline &
\end{tabular}

Table 2 Overall response to treatment and outcome

\begin{tabular}{ll}
\hline & No. of patients \\
\hline Response to primary chemotherapy & $n=65$ \\
Complete response & $16(24 \%)$ \\
Partial response & $41(62 \%)$ \\
Overall response rate & $57(86 \%)$ \\
No change & $6(9 \%)$ \\
Progressive disease & $2(3 \%)$ \\
Surgery & $n=66$ \\
Conservative & $36(55 \%)$ \\
Mastectomy & $17(26 \%)$ \\
No surgery & $13(19 \%)$ \\
Pathological status at surgery & $n=66$ \\
Residual invasive disease & $46(70 \%)$ \\
Complete pathological response & $5(7.5 \%)$ \\
DCIS only & $3(4.5 \%)$ \\
Overall progression-free survival & $n=66$ \\
I year & $87 \%$ \\
2 years & $74 \%$ \\
3 years & $65 \%$ \\
Overall survival & $n=66$ \\
I year & $93 \%$ \\
2 years & $83 \%$ \\
3 years & $77 \%$ \\
\hline
\end{tabular}

$\mathrm{DCIS}=$ ductal carcinoma in situ.

Details of clinical and surgical response to treatment are shown in Table 2. In all, 57 patients (86\%) responded to treatment, $16(25 \%)$ achieving a clinical complete remission (cCR) and $41(63 \%)$ a partial response (PR). One patient was not evaluated for response due to death early on treatment. Following chemotherapy, 12 patients did not have surgical treatment: one refused, two remained inoperable and nine patients achieved a cCR and had radiotherapy alone, as part of a separate research study. As expected, this overall pCR rate of $7.5 \%$ is lower than the $16 \%$ seen in the major primary chemotherapy trial recruiting in our institution during the study period (Smith et al, 2000). This was clearly influenced by the nine patients $(18 \%)$ with a cCR who did not have any surgery following chemotherapy. Median follow-up was 36 months $(1-74)$ and there were 21 relapses and 15 deaths. Progression-free and overall survival figures are detailed in Table 2.

\section{Biological results}

Apoptosis and proliferation Prior to treatment there was a highly significant positive correlation between proliferation, as measured by Ki67 and AI samples (rho $=0.60, P<0.001)$, Figure 1 . Tumour grade was also significantly correlated with both apoptosis and proliferation pretreatment, $P<0.001$. Median AI prechemotherapy was 0.9 (interquartile range (IQ), $0.5-1.5$ ) and at $24 \mathrm{~h}$ postchemotherapy this had increased significantly to 1.60 (IQ 1.0-2.9, $P<0.001$ ), Figure $2 \mathrm{~A}$. The median Ki67 score pre-chemotherapy was 28.5 (IQ $16.1-43.9$ ) and $24 \mathrm{~h}$ following chemotherapy this had fallen significantly to 17.6 (IQ $8.7-26.8, P=0.002$ ), Figure $2 \mathrm{~B}$.

In addition to assessing the impact of chemotherapy on Ki67 and AI individually, the effect on the Ki67/AI ratio, a parameter which we have described as a growth index (GI) (Harper-Wynne et al, 2002) was assessed. There was a significant fall in GI at $24 \mathrm{~h}$, from 28.5 (IQ 19.9-43.5) to 11.5 (IQ 6.0-25.2, $P<0.001$ ), Figure 2C. It was notable that while Ki67 increased in 20 patients and AI decreased in 10 patients, only five patients showed an increase in GI.

The changes in AI and Ki67 are shown according to HER-2 and ER status in Table 3. There were no significance differences in the changes in apoptosis and proliferation seen with chemotherapy according to HER-2 status, but those patients who were ERpositive had a greater proportional fall in proliferation postchemotherapy compared with ER-negative patients $(P=0.006)$.

\section{Relationship of biological indices with clinical response}

Pretreatment indices There was no relationship between pretreatment $\mathrm{AI}$ and overall clinical response, $r=-0.04$, but higher levels of proliferation pretreatment correlated with increased clinical response, $r=-0.31, P<0.025$. Tumour grade was not correlated with overall clinical response, but grade 3 tumours had a greater rate of $\mathrm{cCR}$ rate than grade $2, P=0.007$. A significant relationship was also seen between the GI pretreatment and the clinical response to treatment, $r=0.31, P<0.025$. A significant correlation between both pretreatment proliferation and GI $(P<0.025)$ with clinical response was also seen in the subgroup of patients treated with chemotherapy alone. These were defined as no concomitant tamoxifen or ER-negative patients who received

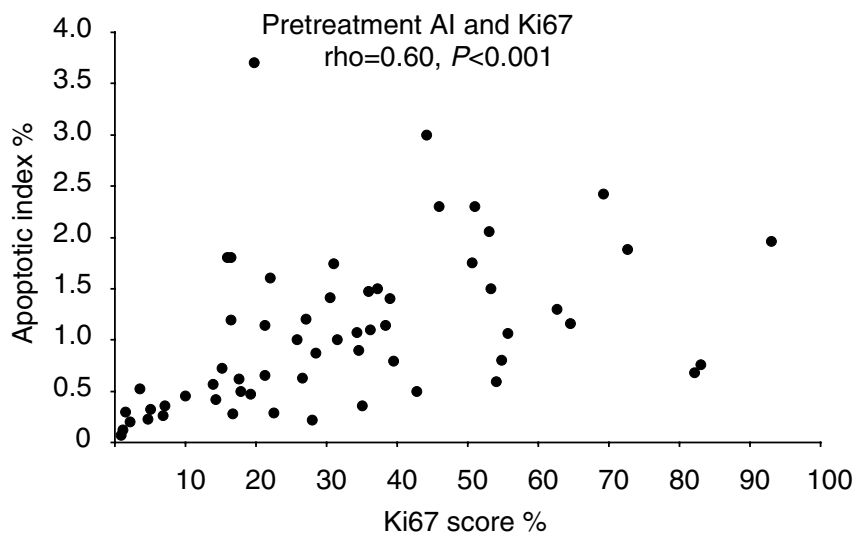

Figure I Correlation of pretreatment Ki67 and Al scores. Each data point represents the scores for an individual tumour (rho $=0.60$, $P<0.001$ ). 

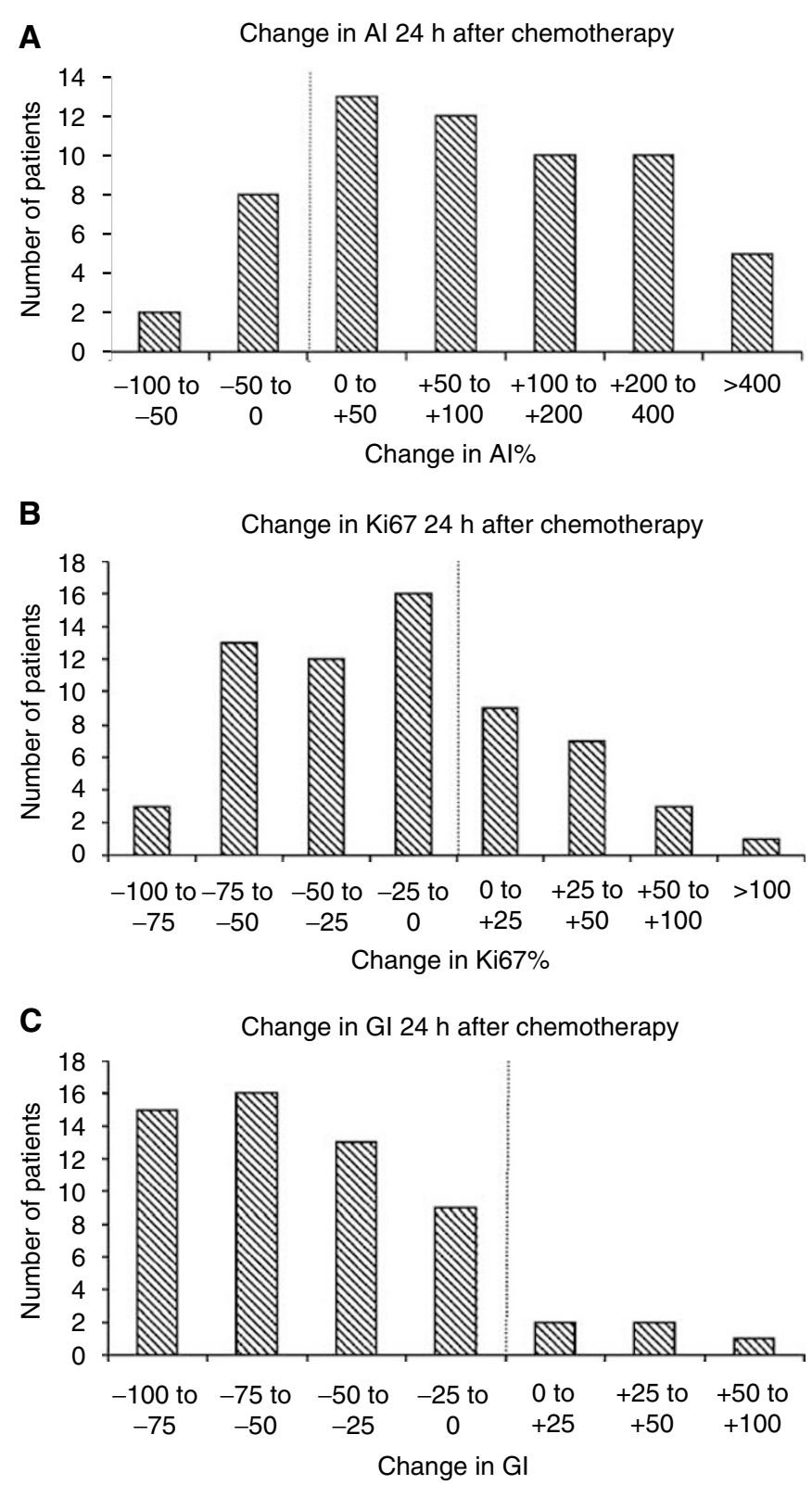

Figure 2 The percentage change in $\mathrm{Al}(\mathbf{A}), \mathrm{Ki} 67(\mathbf{B})$ and $\mathrm{Gl}(\mathbf{C})$ in core biopsies $24 \mathrm{~h}$ after chemotherapy $(n=60)$. The scores have been divided to show a fall to the left of the line and a rise to the right, $(\mathbf{A}) \mathrm{Al}, P<0.00 \mathrm{I}$, (B) Ki67, $P=0.002,(\mathbf{C}) \mathrm{Gl} P<0.00 \mathrm{I}$ )

tamoxifen, where the effects would have been expected to be negligible. No correlation was seen with pretreatment AI and clinical response in this subgroup.

Changes at $24 \mathrm{~h}$ There was no significant relationship seen between clinical response and the biological changes $24 \mathrm{~h}$ after chemotherapy for either AI, Ki67 or GI, Figure 3. This applied to either the whole group or that of the chemotherapy alone group.

\section{Relationship of biological indices with progression-free and overall survival}

On univariate analysis, no relationship was seen between pretreatment AI, Ki67 or GI (assessed as high or low values, above or below the median) with progression-free or overall survival. Similarly, there was no significant relationship between
Table 3 Percentage change from pretreatment levels in Al, Ki67 and Gl after $24 \mathrm{~h}$ of chemotherapy

\begin{tabular}{|c|c|c|c|}
\hline & Al & Ki67 & GI \\
\hline \multicolumn{4}{|l|}{ All } \\
\hline N & 60 & 64 & 58 \\
\hline Median & +81.1 & -17.0 & -53.4 \\
\hline IQ range & +12.7 to +205.65 & -50.0 to +8.5 & -76.5 to -27.4 \\
\hline \multicolumn{4}{|l|}{ ER positive } \\
\hline$N$ & 38 & 43 & 38 \\
\hline Median & +82.5 & -26.1 & -62.6 \\
\hline IQ range & +4.6 to +237.5 & -55.7 to $-I . I I$ & -80.2 to -29.4 \\
\hline \multicolumn{4}{|l|}{ ER negative } \\
\hline $\mathrm{N}$ & 22 & 21 & 20 \\
\hline Median & +81.0 & $-3.2^{\mathrm{a}}$ & -31.3 \\
\hline IQ range & +29.8 to +167.5 & -26.8 to +33.0 & -60.6 to -21.4 \\
\hline \multicolumn{4}{|c|}{ HER-2 positive } \\
\hline $\mathrm{N}$ & 15 & 18 & 15 \\
\hline Median & +33.1 & -12.9 & -37.4 \\
\hline IQ range & +10.8 to +154.6 & -37.3 to +14.0 & -77.3 to -4.7 \\
\hline \multicolumn{4}{|c|}{ HER-2 negative } \\
\hline$N$ & 45 & 46 & 43 \\
\hline Median & +100.0 & -19.4 & -54.0 \\
\hline IQ range & +14.85 to +221.4 & -54.6 to +9.3 & -76.3 to -28.9 \\
\hline
\end{tabular}

the changes in these parameters seen at $24 \mathrm{~h}$ after chemotherapy with progression-free or overall survival. Although those patients with a lower pretreatment GI appeared to have an improved overall survival this was not significant, $P=0.2$, Figure 4 .

\section{DISCUSSION}

In this study, we have demonstrated a significant relationship between AI and Ki67 in breast tumours prior to the initiation of therapy. This is consistent with our previous work (Ellis et al, 1998) and that of others (Lipponen et al, 1994; van Slooten et al, 1998), indicating that tumours with a high rate of apoptosis are also rapidly proliferating. Apoptotic index and Ki67 also correlated positively with high pathological grade. Apoptotic index has been previously shown to be associated with p53 overexpression, but inversely with bcl-2 and ER (Lipponen et al, 1994; Hori et al, 1997; Rochaix et al, 1999). A high proliferation rate in breast tumours is associated with a poorer prognosis (Meyer and Lee, 1980; Silvestrini et al, 1985) as is p53 expression (Silvestrini et al, 1993), whereas ER overexpression is associated with a more favourable prognosis (EBCTCG, 1998b). One might also expect AI to be associated with a poorer outcome, but AI has not been found to have independent prognostic value (Lipponen et al, 1994).

Pretreatment levels of proliferation positively correlated with clinical response. This is consistent with other studies, either using the MIB1 antibody or S-phase fraction (Bonetti et al, 1996; Chevillard et al, 1996; MacGrogan et al, 1996). Ki67 is an antigen that binds to a protein expresssed in late G1-, S-, G2-, and M-phase of the cell cycle, and although most cytotoxic drugs have maximum effect in S-phase, some also act in other phases of the cell cycle, and therefore this finding would be compatable with the biology (Boyer and Tannock, 1998). It is notable, however, that despite most studies concurring that high proliferation is associated with good response to chemotherapy, this same group of patients, as mentioned above, is known to have a poor longterm outcome (Ravaioli et al, 1998). A similar type of relationship with outcome is seen with tumour grade. This may reflect a single biological relationship, since mitotic rate is also a component of tumour grade. There was no relationship between pretreatment AI and clinical response, but the GI, which summates the opposing effects of apoptosis and proliferation, did show a relationship with 
Percentage change in $\mathrm{Al}$ after $24 \mathrm{~h}$ of chemotherapy according to clinical response

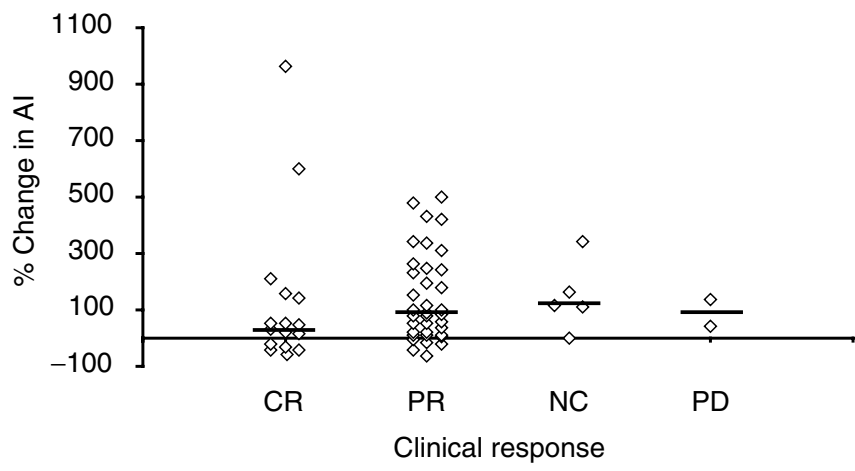

B
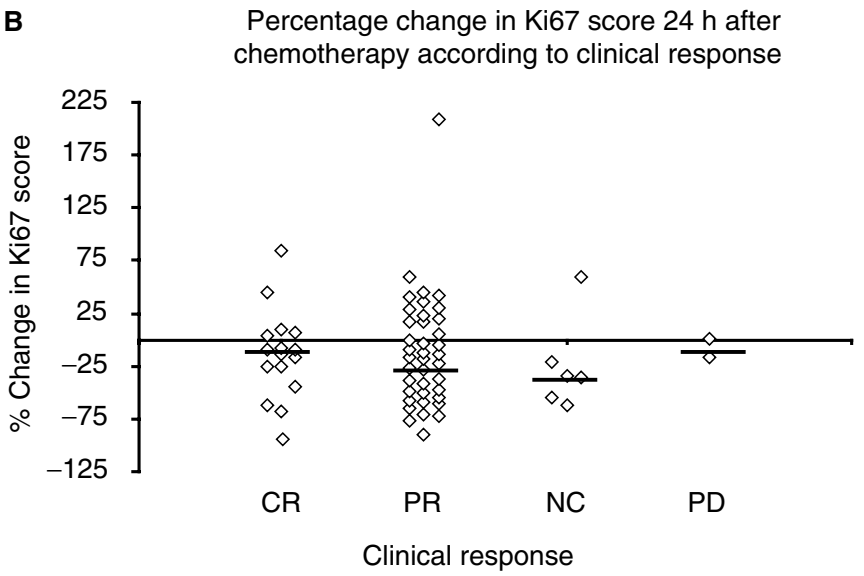

C

Percentage change in $\mathrm{Gl}$ after $24 \mathrm{~h}$ of chemotherapy according to clinical response

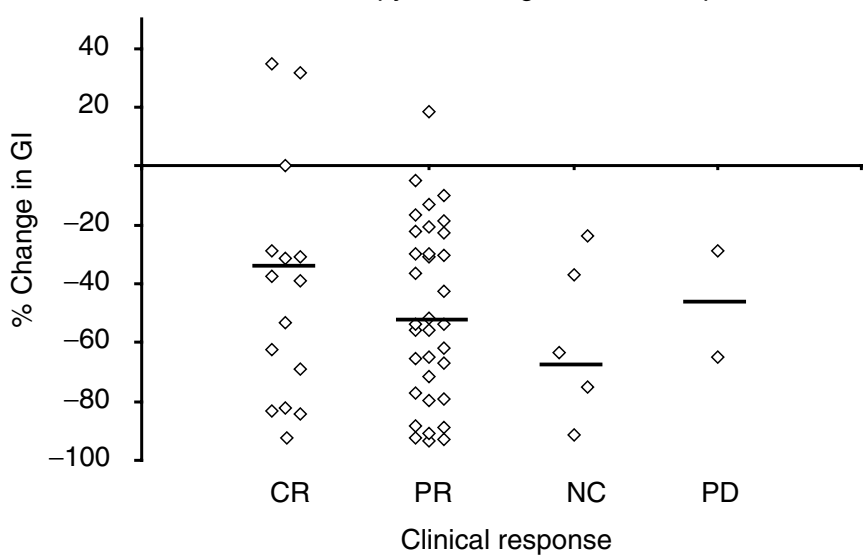

Figure 3 Scattergram illustrating the relationship between change in $\mathrm{Al}$ (A), Ki67 (B), GI (C) and clinical response. Each dot is a value for a tumour and the horizontal line is the median value. PD, progressive disease: NC, no change

clinical response. The degree of correlation with GI was, however, no greater than that with Ki67 alone. Although biological markers pretreatment predicted clinical response, no relationship was seen with disease-free or overall survival.

The data from this study confirm our earlier findings of a significant increase in apoptosis following chemotherapy and extend them with the observed significant fall in proliferation at $24 \mathrm{~h}$. Since changes in apoptosis and/or proliferation are requisites for changes in tumour growth rate, their early measurement during treatment has been investigated on the basis that this might
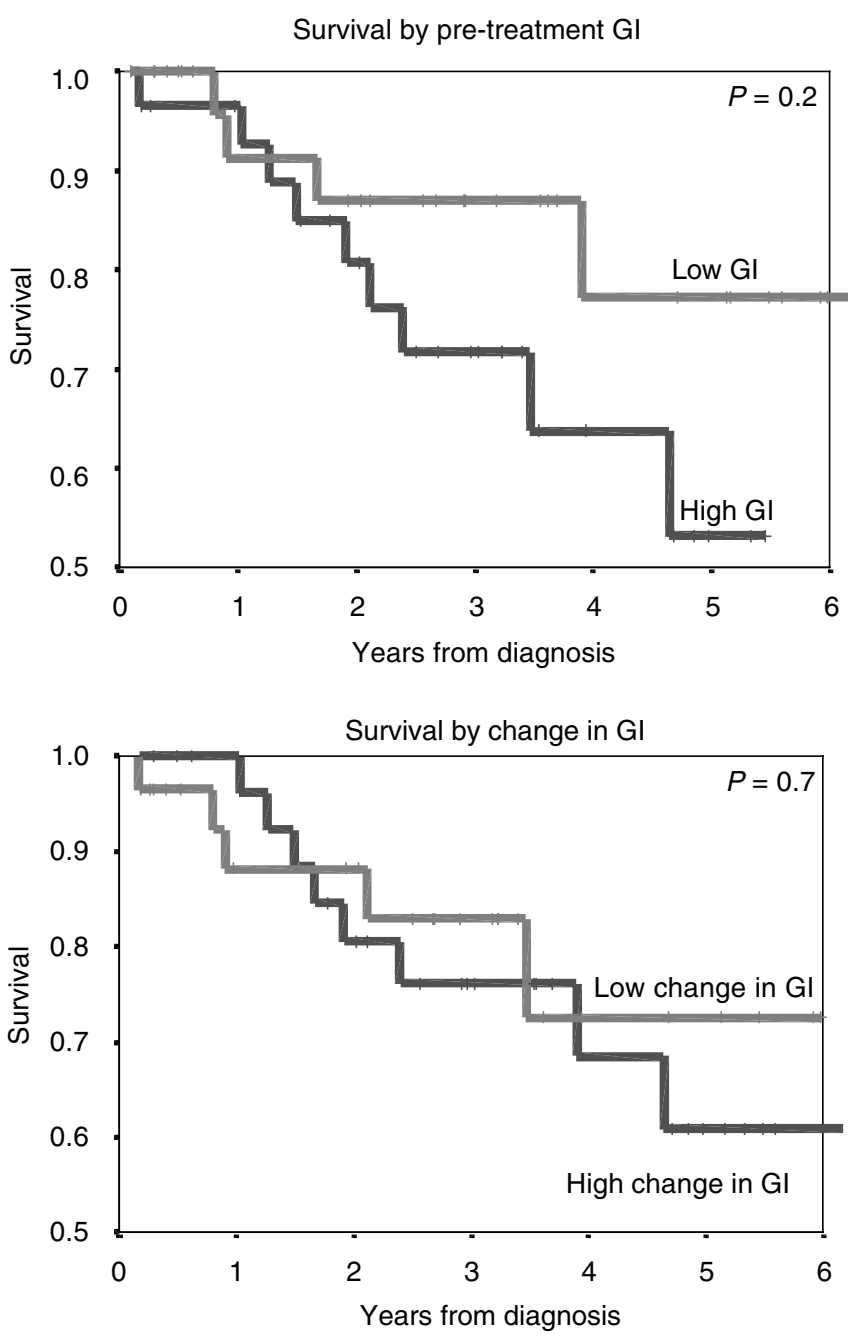

Figure 4 Overall survival curves for patients according to pretreatment tumour growth indices ( $\mathrm{Gl}$ ) (low $\mathrm{Gl}<28.5$ (median value) and high $\mathrm{Gl}$ $>28.5$ ), and change in Gl $24 \mathrm{~h}$ after chemotherapy (low change in Gl $<53.4$ (median value), and high $\mathrm{Gl}>53.4$ ).

enable the prediction of eventual clinical response and long-term benefit from treatment. A small pilot study of 15 patients by Chang et al (2000) using FNA and different laboratory methods did find a significant relationship between early change in apoptosis (at 24$72 \mathrm{~h}$ following treatment) and clinical response (Chang et al, 2000). We were unable to confirm such a relationship between changes at $24 \mathrm{~h}$ and clinical response.

The timing of sampling post chemotherapy may be important in quantifying the increase in AI: the Chang study sampled at either 24 and/or $72 \mathrm{~h}$ postchemotherapy, and used a mean of both measurements when more than one was available. A recent study, again with 15 patients took biopsies at 24 and $48 \mathrm{~h}$, and also failed to show a relationship between apoptosis at $24 \mathrm{~h}$ following chemotherapy, but demonstrated a relationship at $48 \mathrm{~h}$. They noted marked variations though, with one tumour showing a rise in apoptosis at $24 \mathrm{~h}$, but not at $48 \mathrm{~h}$ (Davis et al, 2003). It seems likely that the time of peak increase in apoptosis may vary between patients.

The biopsy at $24 \mathrm{~h}$ in our study was taken after starting chemotherapy alone, but tamoxifen was subsequently given to some patients that may have had an effect on tumour response and therefore possibly confounded any relationship between chemotherapy-induced apoptosis and clinical response. We therefore performed an analysis on the data from patients who did not 
receive tamoxifen, combined with those from patients that were ER negative (where the benefit of any tamoxifen, even if given would have been expected to be negligible). Even in this subgroup no relationship between changes in AI or proliferation at $24 \mathrm{~h}$ and clinical response was seen. A recent study, however, has shown no difference in the response rate to primary chemotherapy with the addition of tamoxifen (von Minckwitz et al, 2001).

Our study was small, but the number of samples would have enabled a correlation of 0.40 to be detected in $90 \%$ of cases. To be clinically useful in predicting response in individual patients, a correlation would need to be substantially greater, and therefore this study would have been able to detect a correlation of clinical utility. Only $62 \%$ of patients had enough tissue in the either biopsy to allow assessment of biological markers by immunohistochemistry, principally due to the large numbers of tumour cells needed to evaluate AI with acceptable precision. This introduces a sampling bias, the data being only applicable to the subgroup with repeatedly cellular samples. The Chang study also noted this problem using FNAs, only 15 out of 28 patients (53\%) having enough material for biological analysis. A 50-60\% success rate also limits the widespread clinical utility of these tests.

Given that there were significant changes in both proliferation and apoptosis after $24 \mathrm{~h}$, which are both likely to contribute to eventual tumour response, we assessed the relationship of GI with clinical response. It was notable that although there were 20 tumours that showed an increase in Ki67 and 10 that showed an decrease in AI, only five showed an increase in the growth index, indicating that the therapy had a beneficial overall effect on tumour growth in $90 \%$ of tumours. While the GI pretreatment correlated with response, changes in GI $24 \mathrm{~h}$ after chemotherapy had no predictive value for response. Thus, while this index may be useful as a guide to overall changes in tumour dynamics, it does not appear to have utility for response prediction.

One of the most significant predictors of relapse-free survival following primary chemotherapy has been shown to be a pCR (Fisher et al, 1998). In our study not all the patients proceeded to surgery, and most of these were patients who achieved a cCR. This confounded the valid assessment of biomarker analysis in relation to $\mathrm{pCR}$.

The lack of a correlation of these early markers with response to chemotherapy or with clinical outcome is disappointing in view of the clear biological rationale for such a relationship and possible reasons for this need to be considered. It should also be noted that a given reduction in proliferation or increase in cell death might lead to regression of a slowly growing tumour, but only slow the growth of a rapidly growing tumour. Thus it may be over simplistic to expect a close relationship between change in these parameters and response measured clinically. Other measurements of response were not performed in this study. Mammography has been shown to be a poorer than clinical measurement (Florentino et al, 2001), but ultrasound maybe more useful and could have allowed measurement of volume changes, which has been used in other studies with primary endocrine treatment (Miller et al, 2001; Harper-Wynne et al, 2002).

Overall we believe this area merits further evaluation, and the study of noninvasive techniques, such as PET may eventually be applicable very early after starting chemotherapy. Also the use of newer techniques such as DNA microarray may improve the predictability of response by combining the change in expression of larger numbers of genes (Assersohn et al, 2002). The analysis growth parameter changes at $24 \mathrm{~h}$ seem to have little clinical utility for predicting individual patient response, and measurement at later time points (e.g., 14 out of 21 days) may hold greater promise (Dowsett et al, 1999).

\section{ACKNOWLEDGEMENTS}

We thank Margaret Hills in the Department of Academic Biochemistry and the Pathology Department at the Royal Marsden NHS Trust for their help in the preparation of the biological samples. The study is supported by a grant from the US Army Breast Cancer Command (DAMD 17-97-1-7335).

\section{REFERENCES}

Assersohn L, Gangi L, Zha Y, Dowsett M, Simon R, Powles TJ, Liu ET (2002) The feasibility of using fine needle aspirations from primary breast cancers for cDNA microarray analysis. Clin Cancer Res 3: 794-801

Bloom HJG, Richardson WW (1957) Histological grading and prognosis in breast cancer. Br J Cancer 11: 359-377

Bonadonna G, Valagussa P, Brambilla C, Ferrari L, Moliterni A, Terenziani M, Zambetti M (1998) Primary chemotherapy in operable breast cancer: eight-year experience at the Milan Cancer Institute. J Clin Oncol 16: $93-$ 100

Bonetti A, Zaninelli M, Rodella S, Molino A, Sperotto L, Piubello Q, Bonetti F, Nortilli R, Turazza M, Cetto GL (1996) Tumor proliferative activity and response to first-line chemotherapy in advanced breast carcinoma. Breast Cancer Res Treat 38: 289-297

Boyer MJ, Tannock IF (1998) Cellular and molecular basis of chemotherapy. In The Basic Science of Oncology, Tannock IF, Hill RP (eds) Vol. 1, pp 353-355. New York: McGraw-Hill

Cameron DA, Anderson ED, Levack P, Hawkins RA, Anderson TJ, Leonard RC, Forrest AP, Chetty U (1997) Primary systemic therapy for operable breast cancer - 10-year survival data after chemotherapy and hormone therapy. Br J Cancer 76: $1099-1105$

Chang J, Ormerod M, Powles TJ, Allred DC, Ashley SE, Dowsett M (2000) Apoptosis and proliferation as predictors of chemotherapy response in patients with breast carcinoma. Cancer 89: 2145-2152

Chang J, Powles TJ, Allred DC, Ashley SE, Clark GM, Makris A, Assersohn L, Gregory RK, Osborne CK, Dowsett M (1999) Biologic markers as predictors of clinical outcome from systemic therapy for primary operable breast cancer. J Clin Oncol 17: 3058-3063
Chevillard S, Pouillart P, Beldjord C, Asselain B, Beuzeboc P, Magdelenat H, Vielh P (1996) Sequential assessment of multidrug resistance phenotype and measurement of S-phase fraction as predictive markers of breast cancer response to neoadjuvant chemotherapy. Cancer 77: 292-300

Davis DW, Buchholz TA, Hess KR, Sahin AA, Valero V, McConkey DJ (2003) Automated quantification of apoptosis after neoadjuvant chemotherapy for breast cancer: early assessment predicts clinical response. Clin Cancer Res 9: 955-960

Detre S, Saclani Jotti G, Dowsett M (1995) A quickscore method for immunohistochemical semiquantitation: validation for oestrogen receptor in breast carcinomas. J Clin Pathol 48: 876-878

Dowsett M, Smith IE, Powles TJ, Salter J, Ellis PA, Johnston SRD, Makris A, Mainwaring P, Gregory RK, Archer C, Chang J, Assersohn L (1999) Biological studies in primary medical therapy of breast cancer: The Royal Marsden experience. In ESO Scientific Updates, Howell A, Dowsett M (eds) Vol. 4, pp 113-125. Amsterdam: Elsevier Science B.V.

EBCTCG (1998a) Polychemotherapy for early breast cancer: an overview of the randomised trials. Early Breast Cancer Trialists' Collaborative Group. Lancet 352: 930 - 942

EBCTCG (1998b) Tamoxifen for early breast cancer: an overview of the randomised trials. Early Breast Cancer Trialists' Collaborative Group. Lancet 351: $1451-1467$

Eisen T, Smith IE, Johnston S, Ellis PA, Prendiville J, Seymour MT, Walsh G, Ashley S (1998) Randomized phase II trial of infusional fluorouracil, epirubicin, and cyclophosphamide versus infusional fluorouracil, epirubicin, and cisplatin in patients with advanced breast cancer. J Clin Oncol 16: $1350-1357$ 
Ellis PA, Smith IE, Detre S, Burton SA, Salter J, A'Hern R, Walsh G, Johnston SR, Dowsett M (1998) Reduced apoptosis and proliferation and increased $\mathrm{Bcl}-2$ in residual breast cancer following preoperative chemotherapy. Breast Cancer Res Treat 48: 107-116

Ellis PA, Smith IE, McCarthy K, Detre S, Salter J, Dowsett M (1997) Preoperative chemotherapy induces apoptosis in early breast cancer. Lancet 349: 849

Fisher B, Brown A, Mamounas E, Wieand S, Robidoux A, Margolese RG, Cruz Jr AB, Fisher ER, Wickerham DL, Wolmark N, DeCillis A, Hoehn JL, Lees AW, Dimitrov NV (1997) Effect of preoperative chemotherapy on local-regional disease in women with operable breast cancer: findings from National Surgical Adjuvant Breast and Bowel Project B18 [see comments]. J Clin Oncol 15: 2483-2493

Fisher B, Bryant J, Wolmark N, Mamounas E, Brown A, Fisher ER, Wickerham DL, Begovic M, DeCillis A, Robidoux A, Margolese RG, Cruz Jr AB, Hoehn JL, Lees AW, Dimitrov NV, Bear HD (1998) Effect of preoperative chemotherapy on the outcome of women with operable breast cancer. J Clin Oncol 16: 2672-2685

Florentino C, Berruti A, Bottini A, Bodini M, Brizzi MP, Brunelli A, Marini U, Allevi G, Agguggni S, Tira A, Aliquati P, Olivetti L, Dogliotti L (2001) Accuracy of mammography and echography versus clinical palpation in the assessment of response to primary chemotherapy in breast cancer patients with operable disease. Breast Cancer Res Treat 69: $143-151$

Forrest AP, Levack PA, Chetty U, Hawkins RA, Miller WR, Smyth JF, Anderson T (1986) A human tumour model. Lancet 2 (8511): $840-842$

Cavrieli Y, Sherman Y, Ben-Sasson SA (1992) Identification of programmed cell death in situ via specific labelling of nuclear DNA fragmentation. $J$ Cell Biol 119: 493-501

Gusterson BA, Gelber RD, Goldhirsch A, Price KN, Save-Soderborgh J, Anbazhagan R, Styles J, Rudenstam CM, Golouh R, Reed R, (1992) Prognostic importance of c-erbB-2 expression in breast cancer. International (Ludwig) Breast Cancer Study Group. J Clin Oncol 10: $1049-1056$

Harper-Wynne CL, Sacks NP, Shenton K, MacNeill FA, Sauven P, Laidlaw IJ, Rayter Z, Miall S, Howes A, Salter J, Hills MJ, Lowe FM, A'Hern R, Nasiri N, Doody D, Iqbal J, Dowsett M (2002) Comparison of the systemic and intratumoral effects of tamoxifen and the aromatase inhibitor vorozole in postmenopausal patients with primary breast cancer. J Clin Oncol 20: 1026-1035

Hori M, Nogami T, Itabashi M, Yoshimi F, Ono H, Koizumi S (1997) Expression of Bcl-2 in human breast cancer: correlation between hormone receptor status, p53 protein accumulation and DNA strand breaks associated with apoptosis. Pathol Int 47: 757-762

Hortobagyi GN, Ames FC, Buzdar AU, Kau SW, McNeese MD, Paulus D, Hug V, Holmes FA, Romsdahl MM, Fraschini G, Mc Bride CM, Martin RG, Montague E (1988) Management of stage III primary breast cancer with primary chemotherapy, surgery, and radiation therapy. Cancer 62: 2507-2516

Lipponen P, Aaltomaa S, Kosma VM, Syrjanen K (1994) Apoptosis in breast cancer as related to histopathological characteristics and prognosis. Eur J Cancer 14: $2068-2073$

MacGrogan G, Mauriac L, Durand M, Bonichon F, Trojani M, de Mascarel I, Coindre JM (1996) Primary chemotherapy in breast invasive carcinoma: predictive value of the immunohistochemical detection of hormonal receptors, p53, c-erbB-2, MiB1, pS2 and GST pi. Br J Cancer 74: 1458-1465

Mainwaring P, Ellis P, Detre S, Smith I, Dowsett M (1998) Comparison of in situ methods to assess DNA cleavage in apoptotic cells in patients with breast cancer. J Clin Pathol 51: 34-37

Meyer JS, Lee JY (1980) Relationships of S-phase fraction of breast carcinoma in relapse to duration of remission, estrogen receptor content, therapeutic responsiveness, and duration of survival. Cancer Res 40: $1890-1896$
Meyn RE, Stephens LC, Hunter NR, Milas L (1994) Induction of apoptosis in murine tumors by cyclophosphamide. Cancer Chemother Pharmacol 33: $410-414$

Meyn RE, Stephens LC, Hunter NR, Milas L (1995) Apoptosis in murine tumors treated with chemotherapy agents. Anticancer Drugs 6: 443-450

Miller AB, Hoogstraten B, Staquet M, Winkler A (1981) Reporting results of cancer treatment. Cancer 47: 207-214

Miller WR, Dixon JM, Cameron DA, Anderson TJ (2001) Biological and clinical effects of aromatase inhibitors in neoadjuvant therapy. J Steroid Biochem Mol Biol 79: $103-107$

NCGfBS (1995) Pathology Reporting in Breast Cancer Screening, Vol. 3. NHSBSP Publications, National Breast Screening Programme

Powles TJ, Hickish TF, Makris A, Ashley SE, O'Brien ME, Tidy VA, Casey S, Nash AG, Sacks N, Cosgrove D (1995) Randomized trial of chemoendocrine therapy started before or after surgery for treatment of primary breast cancer. J Clin Oncol 13: 547-552

Ravaioli A, Bagli L, Zucchini A, Monti F (1998) Prognosis and prediction of response in breast cancer: the current role of the main biological markers. Cell Prolif 31: 113-126

Rochaix P, Krajewski S, Reed JC, Bonnet F, Voigt JJ, Brousset P (1999) In vivo patterns of Bcl-2 family protein expression in breast carcinomas in relation to apoptosis. J Pathol 187: 410-415

Saccani Jotti G, Johnston SR, Salter J, Detre S, Dowsett M (1994) Comparison of new immunohistochemical assay for oestrogen receptor in paraffin wax embedded breast carcinoma tissue with quantitative enzyme immunoassay. J Clin Pathol 47: 900-905

Silvestrini R, Benini E, Daidone MG, Veneroni S, Boracchi P, Cappelletti V, Di Fronzo G, Veronesi U (1993) p53 as an independent prognostic marker in lymph node-negative breast cancer patients. J Natl Cancer Inst 85: $965-970$

Silvestrini R, Daidone MG, Gasparini G (1985) Cell kinetics as a prognostic marker in node-negative breast cancer. Cancer 56: $1982-1987$

Smith IE, A'Hern RP, Howell A, Hickish T, O’Brien M, Mansi J, Wilson C, Robinson A, Pratt W, Price C, Perren T, Laing R (2000) Preoperative continuous infusional (epirubicin, cisplatin and infusional $5 \mathrm{FU}$ ) v. conventional AC chemotherapy for early breast cancer: a phase III multicentre randomised trial by the TOPIC Group. Proc Am J Clin Oncol 19 , abs. 320

Smith IE, Walsh G, Jones A, Prendiville J, Johnston S, Gusterson B, Ramage F, Robertshaw H, Sacks N, Ebbs S (1995) High complete remission rates with primary neoadjuvant infusional chemotherapy for large early breast cancer. J Clin Oncol 13: 424-429

Swain SM, Sorace RA, Bagley CS, Danforth Jr DN, Bader J, Wesley MN, Steinberg SM, Lippman ME (1987) Neoadjuvant chemotherapy in the combined modality approach of locally advanced nonmetastatic breast cancer. Cancer Res 47: 3889-3894

van Slooten HJ, van de Vijver MJ, van de Velde CJ, van Dierendonck JH (1998) Loss of Bcl-2 in invasive breast cancer is associated with high rates of cell death, but also with increased proliferative activity. $\mathrm{Br} J$ Cancer 77: 789-796

von Minckwitz G, Costa SD, Raab G, Blohmer JU, Eidtmann H, Hilfrich J, Merkle E, Jackisch C, Gademann G, Tulusan AH, Eiermann W, Graf E, Kaufmann M (2001) Dose-dense doxorubicin, docetaxel, and granulocyte colony-stimulating factor support with or without tamoxifen as preoperative therapy in patients with operable carcinoma of the breast: a randomized, controlled, open phase IIb study. J Clin Oncol 19: $3506-3515$

Wijsman JH, Jonker RR, Keijzer R, Van de Velde CJH, Cornelisse CJ, Van Dierendonck JH (1993) A new method to detect apoptosis in paraffin sections: in situ labelling of fragmanted DNA. J Histochem Cytochem 41: $7-12$

Wyllie AH, Kerr JFR, Currie AR (1980) Cell death: the significance of apoptosis. Internat Rev Cytol 68: 251-304 